\title{
Risks and complications of transurethral resection of bladder tumors in patients receiving antiplatelet and/or anticoagulant therapy: a retrospective cohort study
}

Tsuzumi Konishi ${ }^{1 *}$ D, Satoshi Washino ${ }^{1}$, Yuhki Nakamura' ${ }^{1}$ Masashi Ohshima ${ }^{1}$, Kimitoshi Saito ${ }^{1}$, Yoshiaki Arai $^{2}$ and Tomoaki Miyagawa'

\begin{abstract}
Background: Information on the safety of transurethral resection of bladder tumors (TURBT) in patients receiving anti-thromboembolic drugs is currently lacking. This study aimed to evaluate the clinical safety of TURBT in patients receiving anti-thromboembolic agents compared with patients not taking these agents and patients who interrupted their use perioperatively.

Methods: We retrospectively analyzed data for patients who underwent TURBT at Jichi Medical University Saitama Medical Center from September 2013 to August 2016.Patients who underwent surgery while receiving antiplatelet and/or anticoagulant drugs were allocated to the continuation group, those who interrupted these drugs comprised the interruption group, and those who did not use these agents were designated as the control group. We compared the patient characteristics, hemoglobin levels, and complications among the three groups.

Results: A total of 174 patients were analyzed including 19, 18, and 137 in the continuation, interruption, and control groups, respectively. There were no significant differences in patient and tumor characteristics, apart from age, among the three groups. Decreases in hemoglobin levels were similar in the continuation, interruption, and control groups $(-0.50 \mathrm{~g} / \mathrm{dl},-0.40 \mathrm{~g} / \mathrm{dl}$, and $-0.50 \mathrm{~g} / \mathrm{dl}$, respectively).Significantly more patients in the continuation group experienced clot retention compared with the control group ( $21 \%$ vs $5 \%, p=0.03)$. Large tumor size tended to be a risk factor for clot retention in the continuation group $(p=0.07)$. No patient in the continuation or interruption group required blood transfusion, compared with two patients (1\%) in the control group. No patients in any of the groups experienced cardiovascular events during their hospital stay or required rehospitalization for hematuria after discharge.

Conclusions: TURBT can be performed safely in patients who continue to take antiplatelet and/or anticoagulant agents, without increasing the risks of severe hemorrhage and blood transfusion. However, the risk of postoperative clot retention may be increased in these patients.
\end{abstract}

Keywords: Anticoagulant, Antiplatelet, Turbt

\footnotetext{
*Correspondence: tsuzumi0203@gmail.com

${ }^{1}$ Department of Urology, Jichi Medical University Saitama Medical Center,

1-847 Amanuma-cho, Omiya-ku, Saitama 330-8503, Japan

Full list of author information is available at the end of the article
} 


\section{Background}

Urologists are encountering increasing numbers of patients with multiple comorbidities associated with the progressive aging of the population. These include coronary artery disease requiring percutaneous coronary arterial intervention with angioplasty, together with the placement of bare metal (BMS) or drug-eluting stents (DES), and cardiac dysrhythmias such as valvular heart disease, deep vein thrombosis, or atrial fibrillation [1]. International guidelines recommend dual antiplatelet (AP) therapy (DAPT) for $\geq 4$ weeks after implantation of BMS, and for 6-12 months after implantation of DES [2, $3]$, while anticoagulant (AC) agents are recommended in patients with cardiac dysrhythmias. Withdrawal of AP and/or AC agents is associated with a significantly increased risk of cardiac ischemic and/or thromboembolic events [4]. Surgeons, physicians, and patients thus face the dilemma of stopping these agents perioperatively to reduce the bleeding risk, and continuing them to avoid the risk of cardiovascular and cerebrovascular events [5]. There is currently no consensus among urologists regarding the perioperative management of patients taking $\mathrm{AP} / \mathrm{AC}$ agents, and information on this issue is lacking [6]. A few recent reports have assessed the safety of continuing to use AP agents during transurethral resection of bladder tumors (TURBT) [5, 7], but there is little information on the safety of TURBT in patients receiving $\mathrm{AC}$ or combined AP/AC therapy. This study aimed to evaluate the clinical safety of TURBT in patients receiving $\mathrm{AP} / \mathrm{AC}$ agents, compared with patients not taking these agents or patients who interrupted their use perioperatively.

\section{Methods}

\section{Patients}

This retrospective observational study was approved by our local institutional review board. Patients who underwent TURBT at Jichi Medical University Saitama Medical Center from September 2013 to August 2016 and who were followed-up for at least 3 months were eligible. Patients who underwent additional procedures at the same time as TURBT or who underwent second TURBT were excluded. Eligible patients were categorized into two groups: patients taking AP and/or AC drugs before surgery (AP/AC group) and those not taking these drugs (control group). Patients in AP/AC group were further categorized into two groups: patients who took AP/AC drugs during surgery (continuation group) and those who interrupted the drugs for the appropriate periods before, during, and after surgery (interruption group). The decision on whether to continue or interrupt AP/AC drugs was made after detailed discussions between patients and doctors (urologists, anesthesiologists, neurologist, and/or, cardiologists), mainly in light of the risk of cardiovascular events.

\section{Device}

TURBT was performed using a UES-40S (Olympus R, Tokyo, Japan) or ESG-400 (Olympus) endoscope.

\section{Management}

In principle, patients were not allowed to walk on the day of surgery, and started to walk the next morning. Blood tests, including hemoglobin levels, were performed on the first postoperative day. Patients were discharged from the hospital after removal of the urethral catheter and spontaneous voiding had been experienced.

\section{Study endpoints}

Patients' characteristics, decreases in hemoglobin levels, median catheter-indwelling duration after TURBT, and complications were compared among the three groups. The endpoints of our study were decrease in hemoglobin level and hemorrhagic complications after TURBT. Decreases in hemoglobin levels were determined as [preoperative hemoglobin level - hemoglobin level on first postoperative day]. Preoperative examinations were performed within 2 months before surgery.

\section{Statistical analysis}

Statistical analysis was performed using GraphPad Prism software version 6.0. Data were compared using Student's $t$-tests, Mann-Whitney U-tests, or $\chi^{2}$ tests. All data are shown as medians and ranges. Statistical significance was set at $p<0.05$.

\section{Results}

\section{Patients and tumor characteristics}

A total of 229 patients were eligible, of whom 31 patients who underwent additional procedures at the same time as TURBT and 24 who underwent second TURBT were excluded. A total of 174 patients were therefore analyzed, including 37 patients in the AP/AC group and 137 in the control group. Among the $37 \mathrm{AP} / \mathrm{AC}$ patients, 19 were in the AP/AC continuation group and 18 were in the interruption group.

Patient and tumor characteristics are shown in Table 1. The age in the interruption group was significantly higher than in the control group $(p=0.003)$, but gender, tumor size, tumor number, $\mathrm{T}$ classification at TURBT, and de novo/recurrence did not differ significantly among the three groups.

\section{Details of medications and reasons for taking AP/AC agents}

Among the 19 patients in the continuation group, seven, three, four, and five were taking a single AP, single AC, DAPT, and AP plus AC, respectively, prior to surgery (Table 2). Of the four patients taking DAPT, three interrupted clopidogrel during the perioperative period, and 
Table 1 Patient and tumor characteristics

\begin{tabular}{|c|c|c|c|c|c|c|c|c|c|}
\hline \multirow[b]{4}{*}{ Median age (range) } & \multicolumn{4}{|c|}{ AP/AC } & & & & & \\
\hline & \multirow{2}{*}{\multicolumn{2}{|c|}{$\begin{array}{l}\text { Continuation (A) } \\
n=19, \mathrm{n}(\%)\end{array}$}} & \multirow{2}{*}{\multicolumn{2}{|c|}{$\begin{array}{l}\text { Interruption (B) } \\
n=18, n(\%)\end{array}$}} & \multirow{2}{*}{\multicolumn{2}{|c|}{$\begin{array}{l}\text { Control (C) } \\
n=137, n(\%)\end{array}$}} & \multicolumn{3}{|l|}{$p$ value } \\
\hline & & & & & & & \multirow{2}{*}{$\begin{array}{r}\text { A vs B } \\
0.14\end{array}$} & \multirow{2}{*}{$\frac{A \text { vs } C}{0.12}$} & \multirow{2}{*}{$\frac{B \text { vs C }}{0.00322}$} \\
\hline & 77 & $(57-89)$ & 81 & $(58-90)$ & 72 & $(38-90)$ & & & \\
\hline \multicolumn{10}{|l|}{ Sex } \\
\hline Male & 17 & $(88 \%)$ & 14 & $(78 \%)$ & 97 & $(71 \%)$ & \multirow[t]{2}{*}{0.40} & \multirow[t]{2}{*}{0.10} & \multirow[t]{2}{*}{0.78} \\
\hline Female & 2 & $(12 \%)$ & 4 & $(22 \%)$ & 40 & $(29 \%)$ & & & \\
\hline \multicolumn{10}{|l|}{ Tumor size } \\
\hline$<1 \mathrm{~cm}$ & 10 & (53\%) & 8 & $(44 \%)$ & 71 & $(52 \%)$ & \multirow[t]{2}{*}{0.75} & \multirow[t]{2}{*}{1.0} & \multirow[t]{2}{*}{0.62} \\
\hline$\geq 1 \mathrm{~cm}$ & 9 & $(47 \%)$ & 10 & $(56 \%)$ & 66 & $(48 \%)$ & & & \\
\hline \multicolumn{10}{|l|}{ Tumor number } \\
\hline Single & 11 & $(58 \%)$ & 12 & $(67 \%)$ & 71 & $(52 \%)$ & \multirow[t]{2}{*}{0.74} & \multirow[t]{2}{*}{0.81} & \multirow[t]{2}{*}{0.32} \\
\hline Multiple & 8 & $(42 \%)$ & 6 & $(33 \%)$ & 66 & $(48 \%)$ & & & \\
\hline \multicolumn{10}{|c|}{ T classification at TURBT } \\
\hline pT0-a & 8 & $(42 \%)$ & 7 & (39\%) & 53 & (39\%) & \multirow[t]{3}{*}{0.43} & \multirow[t]{3}{*}{0.71} & \multirow[t]{3}{*}{0.35} \\
\hline pT1 & 9 & $(47 \%)$ & 10 & $(56 \%)$ & 59 & $(43 \%)$ & & & \\
\hline Min. pT2 & 2 & (11\%) & 1 & $(5 \%)$ & 25 & $(18 \%)$ & & & \\
\hline De novo & 10 & (53\%) & 10 & $(56 \%)$ & 83 & $(61 \%)$ & \multirow[t]{2}{*}{$>0.95$} & \multirow[t]{2}{*}{0.62} & \multirow[t]{2}{*}{0.80} \\
\hline Recurrence & 9 & $(47 \%)$ & 8 & (44\%) & 54 & (39\%) & & & \\
\hline
\end{tabular}

$A P$ antiplatelet agents, $A C$ anticoagulant agents, Min minimum

of the five patients taking AP plus AC, one interrupted the $\mathrm{AC}$ agent during the perioperative period. None of the other patients interrupted any AP/AC agents. At the time of surgery, 11, three, one, and four patients were taking a single AP, single AC, DAPT, and AP plus AC, respectively.

A heparin bridge was performed in nine patients in the interruption group, including four, two, and three patients taking a single AP, single AC, and AP plus AC, respectively, prior to surgery. In the heparin-bridged patients, heparin was started at a dose of $15,000 \mathrm{U} /$ day, adjusted to achieve an activated partial thromboplastin time 1.5-2 times the control value, and then discontinued $4 \mathrm{~h}$ before surgery. Oral AP and/or AC drugs were re-started after no or little hematuria was achieved postoperatively.

The reasons for taking APs and/or ACs are shown in Table 3. Ischemic heart disease (51\%), atrial fibrillation
(30\%), and cerebral infarction (16\%) were the three main reasons.

\section{Anesthesia}

Among the 19 patients in the continuation group, 17 underwent TURBT under general anesthesia and two under spinal anesthesia. In the interruption group, 11 and seven patients underwent TURBT under spinal and general anesthesia, respectively, while 104 and 33 patients in the control group underwent TURBT under spinal and general anesthesia, respectively.

\section{Complications}

Complications during and after TURBT in the three groups are shown in Table 4. Decreases in hemoglobin levels were similar in all three groups $(-0.50 \mathrm{~g} / \mathrm{dl},-0.40 \mathrm{~g} / \mathrm{dl}$, and $-0.50 \mathrm{~g} / \mathrm{dl}$ in the continuation, interruption, and control

Table 2 Details of medication before surgery

\begin{tabular}{|c|c|c|c|c|c|c|c|c|}
\hline \multirow{3}{*}{ Single agent } & \multirow[b]{3}{*}{ Aspirin } & \multicolumn{4}{|c|}{$\begin{array}{l}\text { Continuation, } n=19 \\
n(\%)\end{array}$} & \multicolumn{3}{|c|}{$\begin{array}{l}\text { Interruption, } n=18 \\
n(\%)\end{array}$} \\
\hline & & \multicolumn{2}{|c|}{ Before surgery } & \multicolumn{2}{|c|}{ During surgery } & \multicolumn{2}{|c|}{ Before surgery } & \multirow{2}{*}{$\begin{array}{l}\text { During surgery } \\
-\end{array}$} \\
\hline & & 7 & (37) & 11 & (58) & 11 & (61) & \\
\hline & Clopidogrel & - & & - & & 1 & (5) & - \\
\hline & $A C$ & 3 & (16) & 3 & (16) & 3 & $(17)$ & - \\
\hline \multirow[t]{2}{*}{ Combination } & DAPT & 4 & $(21)$ & 1 & (5) & 0 & (0) & - \\
\hline & $A P+A C$ & 5 & (26) & 4 & (21) & 3 & (17) & - \\
\hline
\end{tabular}


Table 3 Reasons for medication

\begin{tabular}{lllllll}
\hline & \multicolumn{2}{l}{$\begin{array}{l}\text { Continuation } \\
n=19, \mathrm{n}(\%)\end{array}$} & \multicolumn{2}{l}{$\begin{array}{l}\text { Interruption } \\
n=18, n(\%)\end{array}$} & \multicolumn{2}{l}{ Total } \\
& \multicolumn{2}{l}{$n=37, n(\%)$} \\
\hline $\mathrm{HD}$ & 12 & $(63 \%)$ & 7 & $(39 \%)$ & 19 & $(51)$ \\
$\mathrm{AF}$ & 5 & $(26 \%)$ & 6 & $(33 \%)$ & 11 & $(30)$ \\
$\mathrm{Cl}$ & 0 & $(0 \%)$ & 6 & $(33 \%)$ & 6 & $(16)$ \\
Primary prevention & 2 & $(11 \%)$ & 1 & $(6 \%)$ & 3 & $(8)$ \\
Others & 3 & $(16 \%)$ & 0 & $(0 \%)$ & 3 & $(8)$ \\
\hline
\end{tabular}

IHD ischemic heart disease, $A F$ atrial fibrillation, $C /$ cerebral infarction

groups, respectively). Significantly more patients (21\%, $4 / 19$ ) in the continuation group experienced clot retention compared with the control group (5.0\%, 7/ 140) $(p=0.03)$. All four patients with clot retention in the continuation group were only taking aspirin (Table 5). Two of them experienced clot retention during catheterization (postoperative day [POD] 1 and POD3) and required surgical reintervention, while the other two experienced clot retention after catheter removal (POD3 and POD21), which was improved by bladder drainage and catheter replacement. Two $(11 \%)$ and three patients $(2 \%)$ in the continuation and control groups required surgical reintervention to stop bleeding, respectively. The median duration of catheter-indwelling was significantly longer in the continuation group (2 days) compared with the control group ( 1 day) $(p=0.03)$. However, there was no significant difference in hospitalization days after surgery among the three groups. No patient in the continuation or interruption group required blood transfusion, compared with two patients (1\%) in the control group. No patients in any of the groups experienced cardiovascular events during their hospital stay, or required rehospitalization for hematuria during the 3 months after discharge.
Risk factors for clot retention in patients continuing AP/AC

We evaluated the risk factors for clot retention in patients continuing $\mathrm{AP} / \mathrm{AC}$ drugs by comparing patients in the continuation group with $(n=4)$ and without clot retention $(n=15)$ (Table 6). Large tumors tended to be a risk factor for clot retention $(p=0.07)$, though the difference was not significant. However, age, tumor number, $T$ classification at TURBT, and type and number of AP/AC agents were unrelated to clot retention $(p>0.1)$.

\section{Discussion}

The American Urologic Association and the International Consultation on Urological Disease produced a collaborative review of Anticoagulation and Antiplatelet Therapy in Urologic Practice [1], which stated that urologists need to understand the factors affecting the safe and effective use of AP and AC prophylaxis, as well as the risks posed by their withdrawal. These risks include venous and arterial thromboembolism, as well as major adverse cerebrovascular and cardiac events, which may be more life-altering than hemorrhage. Although the review also considered the management of $\mathrm{AP} / \mathrm{AC}$ drugs during various urologic procedures, including shock wave lithotripsy, ureteroscopy with laser lithotripsy, percutaneous nephrolithotomy, laser prostatectomy, transurethral resection of the prostate, ultrasound-guided prostate biopsy, radical prostatectomy, and surgical renal procedures, it did not discuss the appropriate management of patients undergoing TURBT. A review of AP therapy in patients with coronary stents who underwent urologic surgery [8] included TURBT as a high risk procedure for bleeding. This review recommended that APs should be discontinued in patients at low thromboembolic risk undergoing TURBT, while elective surgery should be postponed if possible in patients at intermediate or high risk. In non-

Table 4 Surgical outcomes and complications

\begin{tabular}{|c|c|c|c|c|c|c|c|c|c|}
\hline \multirow[b]{4}{*}{$\begin{array}{l}\text { Median } \mathrm{Hb} \text { decrease } \\
\mathrm{g} / \mathrm{dL} \text { (range) }\end{array}$} & \multicolumn{4}{|c|}{ AP/AC } & & & & & \\
\hline & \multirow{2}{*}{\multicolumn{2}{|c|}{$\begin{array}{l}\text { Continuation (A) } \\
n=19, n(\%)\end{array}$}} & \multirow{2}{*}{\multicolumn{2}{|c|}{$\begin{array}{l}\text { Interruption (B) } \\
n=18, n(\%)\end{array}$}} & \multirow{2}{*}{\multicolumn{2}{|c|}{$\begin{array}{l}\text { Control (C) } \\
n=137, n(\%)\end{array}$}} & \multicolumn{3}{|c|}{$p$ value } \\
\hline & & & & & & & \multirow{2}{*}{$\frac{A \text { vs } B}{0.27}$} & \multirow{2}{*}{$\begin{array}{l}\text { A vs C } \\
0.20\end{array}$} & \multirow{2}{*}{$\frac{B \text { vs C }}{0.48}$} \\
\hline & -0.5 & $(--2.8-0.6)$ & -0.4 & $(-1.6-1.2)$ & -0.5 & $(-3.1-2.6)$ & & & \\
\hline $\begin{array}{l}\text { Median catheter indwelling } \\
\text { days (range) }\end{array}$ & 2 & $(1-8)$ & 1 & $(1-5)$ & 1 & $(0-20)$ & 0.06 & 0.03 & 0.50 \\
\hline Clot retention & 4 & $(21)$ & 0 & (0) & 7 & (5) & 0.11 & 0.03 & $>0.95$ \\
\hline Surgical reintervention & 2 & (11) & 0 & (0) & 3 & (2) & 0.49 & 0.11 & $>0.95$ \\
\hline Transfusion & 0 & $(0)$ & 0 & (0) & 2 & (1) & $>0.95$ & $>0.95$ & $>0.95$ \\
\hline Cardiovascular events & 0 & $(0)$ & 0 & (0) & 0 & (0) & $>0.95$ & $>0.95$ & $>0.95$ \\
\hline $\begin{array}{l}\text { Median days of hospital stay after } \\
\text { surgery (range) }\end{array}$ & 5 & $(3-12)$ & 5 & $(3-7)$ & 5 & $(2-14)$ & 0.57 & 0.18 & 0.50 \\
\hline Re-admission & 0 & $(0)$ & 0 & (0) & 0 & (0) & $>0.95$ & $>0.95$ & $>0.95$ \\
\hline
\end{tabular}

$A P$ antiplatelet agents, $A C$ anticoagulant agents, $H b$ hemoglobin 
Table 5 Cases with clot retention in AP/AC continuation group

\begin{tabular}{lllllllll}
\hline & Sex & Medication & Tumor no. & $\begin{array}{l}\text { Tumor } \\
\text { size }(\mathrm{cm})\end{array}$ & pT stage & $\begin{array}{l}\text { POD at catheter } \\
\text { removal }\end{array}$ & $\begin{array}{l}\text { Onset of clot } \\
\text { retention (POD) }\end{array}$ & Treatment \\
\hline Case 1 & M & Aspirin & 2 & 1.5 & $a$ & $(-)$ & 1 & Surgical reinterventiom \\
Case 2 & M & Aspirin & 2 & 3 & 1 & $(-)$ & 3 & Surgical reinterventiom \\
Case 3 & $M$ & Aspirin & 1 & 2 & 1 & 1 & 21 & Bladder drainage \\
Case 4 & M & Aspirin & 6 & 2 & 1 & 2 & 3 & Bladder drainage and irrigation
\end{tabular}

$A P$ antiplatelet agents, $A C$ anticoagulant agents, no number, $P O D$ postoperative day, $M$ male

deferrable cases, aspirin should be continued if possible, P2Y12 inhibitors should be discontinued 5 days before surgery and resumed within 24-72 h with a loading dose, and bridge therapy with glycoprotein IIb/IIIa inhibitors is recommended if aspirin is discontinued, though these agents may be clinically unavailable, as in Japan. However, no replacement therapy has yet been validated prospectively [9].

International guidelines for percutaneous cardiovascular intervention advocate DAPT for $\geq 4$ weeks after BMS implantation and for 6-12 months after DES implantation [2], and premature withdrawal of AP agents was shown to be related to a higher risk of cardiac ischemic or thromboembolic events associated with stent thrombosis [3]. This rare but life-threatening complication usually manifests as acute myocardial infarction, with a mortality of $10 \%-40 \%$, though the incidence of stent thrombosis can be increased up to 90-fold following premature discontinuation of DAPT [10]. APs provide effective long-term secondary prevention of vascular events and ischemic stroke after acute or transient ischemic stroke. A systematic review of 287 randomized trials in patients at high risk of vascular occlusive events found that AP agents significantly decreased the risk of stroke by $31 \%$ [11]. Interruption of aspirin therapy was a significant risk factor for a stroke event within 4 weeks after aspirin discontinuation (odds ratio 3.4), with the main reasons for interrupting aspirin therapy being surgery, the treating physician's decision that the therapy had no clear clinical benefit, and bleeding complications [12]. Five of 493 (1\%) patients who stopped continuous ACs to allow the performance of dental procedures developed severe embolic complications, resulting in four deaths [4]. Overall, discontinuation of AP/AC agents is associated with severe thrombotic events and these drugs should be continued if at all possible.

Piccozi et al. recently demonstrated that continued use of aspirin monotherapy did not increase overall bleeding or reintervention risks in patients undergoing TURBT ( $2.8 \%$ in the aspirin group vs $1.9 \%$ in the control group) [5]. Camignani et al. assessed 12 patients receiving DAPT who underwent TURBT and demonstrated that no patients required reintervention for hemostatic purposes, but three (25\%) of the 12 patients experienced clot retention after removal of the bladder catheter, all of which cases were resolved by replacing the catheter [7]. In the current study, we demonstrated that continuing $\mathrm{AP} / \mathrm{AC}$ agents did not lead to increased blood loss or an increased incidence of blood transfusion compared with patients not taking or interrupting $\mathrm{AP} / \mathrm{AC}$ agents. However, the incidence of clot retention was significantly increased in the AP/AC continuation group (21\%) compared with the control group (5\%). Interestingly, all four patients with clot retention received aspirin monotherapy, whereas patients

Table 6 Risk factors for clot retention in AP/AC continuation group

\begin{tabular}{|c|c|c|c|c|c|c|}
\hline & & \multicolumn{2}{|c|}{$\begin{array}{l}\text { Clot retention (+) } \\
n=4, n(\%)\end{array}$} & \multicolumn{2}{|c|}{$\begin{array}{l}\text { Clot retention }(-) \\
n=15, n(\%)\end{array}$} & \multirow{2}{*}{$\begin{array}{c}p \text { value } \\
0.76\end{array}$} \\
\hline \multicolumn{2}{|l|}{ Median age (range) } & 77 & $(63-89)$ & 77 & $(57-85)$ & \\
\hline \multicolumn{2}{|c|}{ Median tumor size, cm (range) } & 2 & $(1.5-3)$ & 0.8 & $(0.5-3)$ & 0.07 \\
\hline \multirow[t]{2}{*}{ Tumor number } & Single & 1 & (25) & 10 & $(67)$ & \multirow[t]{2}{*}{0.26} \\
\hline & Multiple & 3 & (75) & 5 & (33) & \\
\hline \multirow[t]{3}{*}{ T classification at TURBT } & pTa & 1 & (25) & 7 & $(47)$ & \multirow[t]{3}{*}{0.43} \\
\hline & pT1 & 3 & (75) & 6 & $(40)$ & \\
\hline & Min. pT2 & 0 & $(0)$ & 2 & (13) & \\
\hline \multirow[t]{3}{*}{ AP/AC drugs } & Single AP & 4 & (100) & 7 & $(47)$ & \multirow[t]{3}{*}{0.16} \\
\hline & Single AC & 0 & (0) & 3 & $(20)$ & \\
\hline & Combination & 0 & (0) & 5 & (33) & \\
\hline
\end{tabular}


taking $\mathrm{AC}$ agents or combined $\mathrm{AP} / \mathrm{AC}$ agents did not experience clot retention. Large tumor size appeared to be a risk factor for clot retention, though the result was not statistically significant. Overall, these results suggest that TURBT can be performed in patients continuing to take $\mathrm{AP} / \mathrm{AC}$ agents, including a combination of $\mathrm{AP} / \mathrm{AC}$ agents, without increasing the risk of severe hemorrhage, though the risk of clot formation after surgery might be increased, especially in patients with large tumors. However, the incidence of complications in patients who interrupted AP/AC agents was similar to that in patients not taking these drugs, suggesting that it might be preferable to interrupt $\mathrm{AP} / \mathrm{AC}$ agents in patients with a low thromboembolic risk, with a heparin bridge in patients taking ACs. However, the use of heparin-bridging therapy is controversial, and a recent study found that it did not reduce the risk of arterial thromboembolism compared with no bridging therapy in patients with stable nonvalvular atrial fibrillation [13]. In patients taking novel oral ACs, short-term interruption of these agents during the perioperative period might be possible because of their rapid offset and onset of anticoagulant activity [14].

There were several limitations to the present study. Notably, the retrospective nature of the study increased the risk of patient selection bias, and the sample size was small because of the small portion of patients taking $\mathrm{AP}$ and/or AC agents undergoing TURBT, which might underestimate the risk of taking these agents while undergoing TURBT. However, to the best of our knowledge, this is the first study to compare complications among patients who continued AP/AC, those who interrupted the treatment, and those not taking these agents, and to demonstrate that major bleeding complications were relatively rare, even in patients taking DAPT or a combination of AP and AC agents. However, further large prospective studies are therefore needed to verify these results.

\section{Conclusion}

TURBT can be performed safely in patients who continue to use AP and/or AC agents without increasing the risks of severe hemorrhage and blood transfusion. However, the risk of clot retention after surgery may be increased in these patients.

\section{Abbreviations}

AC: anticoagulant; AP: antiplatelet; BMS: bare metal stents; DAPT: dual antiplatelet therapy; DES: drug-eluting stents; M: male; Min: minimum POD: postoperative day; TURBT: transurethral resection of bladder tumors

\section{Acknowledgments}

We would like to thank the cardiologists and anesthesiologists at Jichi Medical University Saitama Medical Center for their cooperation and insightful comments. We thank Susan Furness, PhD, from Edanz Group (www.edanzediting.com/ac) for editing a draft of this manuscript.
Funding

None

Availability of data and materials

The dataset analyzed in this study is available from the corresponding author by request.

\section{Authors' contributions \\ TK was a major contributor to the conception and design of the study and in drafting the manuscript. SW and MT analyzed and interpreted the patient data. YN, MO, KS, and YA provided administrative and technical support, including data acquisition. All of the authors read and approved the final manuscript.}

Ethics approval and consent to participate

This study was approved by the ethics committee of Jichi Medical University Saitama Medical Center (reference no. Rin 15-99). Additional informed consent was not required due to the retrospective nature of this study.

\section{Consent for publication}

Not applicable.

\section{Competing interests}

The authors declare that they have no competing interests.

\section{Publisher's Note}

Springer Nature remains neutral with regard to jurisdictional claims in published maps and institutional affiliations.

\section{Author details}

${ }^{1}$ Department of Urology, Jichi Medical University Saitama Medical Center, 1-847 Amanuma-cho, Omiya-ku, Saitama 330-8503, Japan. ${ }^{2}$ Department of Urology, Nishi-Omiya Hospital, 1-1173 Mihashi, Omiya-ku, Saitama 330-0856, Japan.

Received: 8 June 2017 Accepted: 5 December 2017

Published online: 12 December 2017

\section{References}

1. Culkin D, Exaire E, Green D, Soloway M, Gross A, Desai M, White J, Lightner D. Anticoagulation and Antiplatelet therapy in urological practice: ICUD/AUA review paper. J Urol. 2014;192(4):1026-34.

2. Kolh P, Wijns W, Danchin N, Di Mario C, Falk V, Folliguet T, Garg S, Huber K, James S, Knuuti J, Lopez-Sendon J, Marco J, Menicanti L, Ostojic M, Piepoli M, Pirlet C, Pomar J, Reifart N, Ribichini F, Schalij M, Sergeant P, Serruys P, Silber S, Uva M, Taggart D, Torracca L, Valgimigli M, Wijns W, Witkowski A. 2014 ESC/EACTS guidelines on myocardial revascularization: the task force on myocardial revascularization of the European Society of Cardiology (ESC) and the European Association for Cardio-Thoracic Surgery (EACTS). Developed with the special contribution of the European Association of Percutaneous Cardiovascular Interventions (EAPCI). Eur I Cardiothorac Surg. 2014:46(4):517-92.

3. Biondi-Zoccai G, Lotrionte M, Agostoni P, Abbate A, Fusaro M, Burzotta F, Testa L, Sheiban I, Sangiorgi G. A systematic review and meta-analysis on the hazards of discontinuing or not adhering to aspirin among 50279 patients at risk for coronary artery disease. Eur Heart J. 2006;27(22):2667-74.

4. Wahl M. Dental surgery in anticoagulated patients. Arch of Intern Med. 1998;158(15):1610-6.

5. Picozzi S, Marenghi C, Ricci C, Bozzini G, Casellato S, Carmignani L. Risks and complications of transurethral resection of bladder tumor among patients taking antiplatelet agents for cardiovascular disease. Surg Endosc. 2014; 28(1):116-21.

6. Eberli D, Chassot P, Sulser T, Samama C, Mantz J, Delabays A, Spahn D. Urological surgery and Antiplatelet drugs after cardiac and Cerebrovascular accidents. J Urol. 2010;183(6):2128-36.

7. Carmignani L, Picozzi S, Stubinski R, Casellato S, Bozzini G, Lunelli L, Arena D. Endoscopic resection of bladder cancer in patients receiving double platelet antiaggregant therapy. Surg Endosc. 2011;25(7):2281-7.

8. Naspro R, Rossini R, Musumeci G, Gadda F, Da Pozzo L. Antiplatelet therapy in patients with coronary stent undergoing urologic surgery: is it still no Man's land? Eur Urol. 2013;64(1):101-5. 
9. Samama C, Bastien O, Forestier F, Denninger M, Isetta C, Juliard J, Lasne D, Leys D, Mismetti P, Grp E. Antiplatelet agents in the perioperative period: expert recommendations of the French Society of Anesthesiology and Intensive Care (SFAR) 2001 - summary statement. Can J Anaesth. 2002:49(6):S26-35.

10. lakovou I, Schmidt T, Bonizzoni E, Ge L, Sangiorgi G, Stankovic G, Airoldi F, Chieffo A, Montorfano M, Carlino M, Michev I, Corvaja N, Briquori C, Gerckens U, Grube E, Colombo A. Incidence, predictors, and outcome of thrombosis after successful implantation of drug-eluting stents. JAMA. 2005; 293(17):2126-30

11. Straus S, Majumdar S, McAlister F. New evidence for stroke prevention scientific review. JAMA. 2002;288(11):1388-95.

12. Llinas R. Could discontinuation of aspirin therapy be a trigger for stroke? Nat Clin Pract Neurol. 2006;2(6):300-1.

13. Bouillon K, Bertrand M, Boudali L, Ducimetiere P, Dray-Spira R, Zureik M. Short-Term Risk of Bleeding During Heparin Bridging at Initiation of Vitamin K Antagonist Therapy in More Than 90000 Patients with Nonvalvular Atrial Fibrillation Managed in Outpatient Care. J Am Heart Assoc. 2016:5(11).

14. Latona J, Rahman A. Management of oral anticoagulation in the surgical patient. ANZ J Surg. 2015;85(9):620-5.

\section{Submit your next manuscript to BioMed Central} and we will help you at every step:

- We accept pre-submission inquiries

- Our selector tool helps you to find the most relevant journal

- We provide round the clock customer support

- Convenient online submission

- Thorough peer review

- Inclusion in PubMed and all major indexing services

- Maximum visibility for your research

Submit your manuscript at www.biomedcentral.com/submit 